\title{
Fabrication of holes using electric discharge machining on Titanium alloys
}

\author{
Vishal Kumar' ${ }^{1}$ J. Ramkumar ${ }^{1 *}$ and R. K. Gupta ${ }^{2}$
}

${ }^{1}$ Indian Institute of Technology Kanpur, Department of Mechanical Engineering, 208016, India

${ }^{2}$ Vikram Sarabhai Space Centre, Materials and Mechanical Entity, Trivandrum, 695022, India

*Email: jrkumar@iitk.ac.in

Commercially pure (CP70) titanium is used for aerospace application because of its high specific strength, thermo-mechanical strength and corrosion resistance. However, its poor thermal conductivity and strong alloy forming tendency with tool material make conventional machining a challenging task [1]. Electric discharge machining (EDM) processes, being independent of workpiece mechanical properties, are found suitable for machining these materials. Holes of diameter $6 \mathrm{~mm}$ in CP70 sheets of $1 \mathrm{~mm}$ thickness are required to be drilled for bracket joining operation in aerospace components. Electric discharge trepanning operation is proposed for fabricating these holes with a hypothesis that it can reduce heat affected zone and improve geometry. The holes of diameter $6 \mathrm{~mm}$ formed by this process using tool electrode of diameter $0.5 \mathrm{~mm}$ are shown in Figure 1.

Manufacturers of EDM tools do not provide optimal parameters to be followed for processing advanced materials [2]. Hence, drilling experiments were first conducted on a $\mu$-EDM tool (Mikrotools DT-110) using 0.5 $\mathrm{mm}$ tungsten carbide electrode at varying gap voltage and capacitance. A tool spindle rotation of $100 \mathrm{rpm}$ is given to improve flushing of debris. Evaluations of MRR, tool wear and overcut have been carried out, which were further analyzed using Design-Expert ${ }^{\circledR}$ software. The response behaviours are shown in Figure 2 and Figure 3.

Based on the data analysis, optimum sets of parameters selected for experimental study of trepanning operation are given in Table 1.

Table 1: Parameters selected for ED trepanning

\begin{tabular}{lll}
\hline $\begin{array}{l}\text { Sl. } \\
\text { No. }\end{array}$ & $\begin{array}{l}\text { Capacitance, } \\
\mathrm{nF}\end{array}$ & $\begin{array}{l}\text { Gap } \\
\text { Voltage, } \mathrm{V}\end{array}$ \\
\hline 1 & 400 & 100 \\
2 & 400 & 110 \\
3 & 400 & 120 \\
4 & 400 & 130 \\
\hline
\end{tabular}

Further, evaluation of MRR and geometry were carried out, and it is observed that optimum set of parameters for trepanning operation is gap voltage of $120 \mathrm{~V}$ and capacitance of $400 \mathrm{nF}$, which provides maximum MRR with improved geometry.
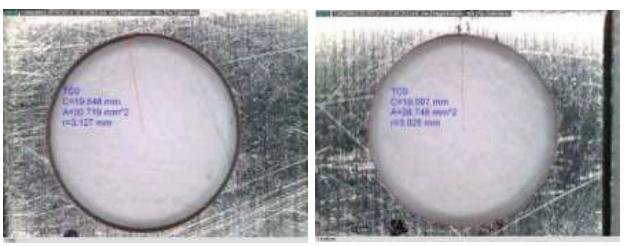

Figure 1: Electric Discharge trepanned holes of diameter $6 \mathrm{~mm}$

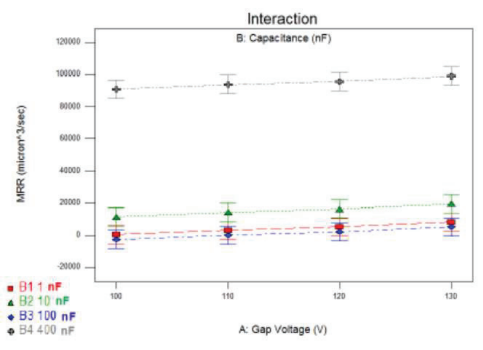

Figure 2: Relation between machining time and gap voltage at difference capacitance values

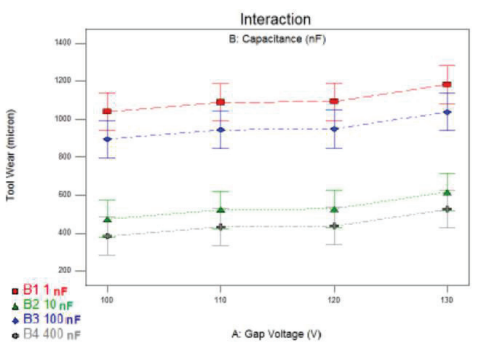

Figure 3: Relation between tool wear and gap voltage at difference capacitance values

\section{References}

1. F. Nourbakhsh, K.P. Rajurkar, A.P. Malse, J.Cao, Wire electro-discharge machining of titanium alloys, Procedia CIRP 5 (2013) 13-18.

2. F. Klocke, M. Holsten, L. Hensgen, A. Klink, Experimental Investigations on Sinking-EDM of Seal Slots in Gamma-TiAl, Procedia CIRP 24 (2014) 92-96. 